\title{
Effect of Torulaspora delbrueckii Yeast on the Anthocyanin and Flavanol Concentrations of Cabernet franc and Pinotage Wines
}

\author{
P.P. Minnaar ${ }^{1 *}$, N. Ntushelo ${ }^{2}$, Z. Ngqumba ${ }^{1}$, V. van Breda ${ }^{1}$, N.P. Jolly ${ }^{1}$ \\ (1) ARC Infruitec-Nietvoorbij, Private Bag X5026, Stellenbosch 7600, South Africa \\ (2) ARC Biometry, Private Bag X5026, Stellenbosch 7600, South Africa
}

Submitted for publication: May 2014

Accepted for publication: June 2014

Key words: $S$. cerevisiae, sensory attributes, principal component analysis

\begin{abstract}
Pinotage and Cabernet franc grape must were inoculated with Saccharomyces cerevisiae and Torulaspora delbrueckii yeasts. Differences in colour were observed between Pinotage (S. cerevisiae) and Pinotage (T. delbrueckii) wines, whereas differences in berry and herbaceous character were observed between Cabernet franc ( $S$. cerevisiae) and Cabernet franc ( $T$. delbrueckii) wines. Mouthfeel properties between treatments for both wines were not significantly different. Overall quality was slightly higher in wines inoculated with $T$. delbrueckii compared to wines inoculated with $S$. cerevisiae. Anthocyanins and flavanols measured in Pinotage wines made with $T$. delbrueckii were higher compared to Pinotage must inoculated with $S$. cerevisiae. Cabernet franc wines made with $S$. cerevisiae were higher in anthocyanin glycoside and flavanol concentrations compared to Cabernet franc wines made with $T$. delbrueckii. Insignificant differences in acetylated and coumarylated anthocyanins were evident between Cabernet franc (S. cerevisiae) and Cabernet franc (T. delbrueckii) wines. Principal component analysis showed that epigallocatechin gallate, epicatechin gallate, procyanidin $\mathrm{B} 2$, peonidin 3-O-glucoside, delphinidin 3-(6-acetyl) glucoside, petunidin 3-(6-acetyl) glucoside, malvidin 3-(6-acetyl) glucoside and malvidin 3-O-glucoside concentrations were highest in Pinotage wines inoculated with $T$. delbrueckii. Cabernet franc wines inoculated with $S$. cerevisiae yeasts were highest in malvidin 3-(6-p-coumaroyl) glucoside, petunidin 3-(6-p-coumaroyl) glucoside, petunidin 3-O-glucoside, epicatechin gallate and epigallocatechin gallate concentrations. Total anthocyanins were highest in Pinotage (S. cerevisiae) wines and Cabernet franc ( $T$. delbrueckii) wines. Flavanols were highest in Pinotage (T. delbrueckii) and Cabernet franc (S. cerevisiae) wines. It is evident from the results that yeast species has an impact on the flavonoid concentrations within a grape variety.
\end{abstract}

\section{INTRODUCTION}

Research results in reviewed articles showed that nonSaccharomyces yeast species contribute positively to the aroma and flavour of wines (Jolly et al., 2006; Comitini et al., 2011; Jolly et al., 2014). Certain metabolic products resulting from non-Saccharomyces yeast growth include terpenoids, esters, higher alcohols, glycerol, acetaldehyde, acetic acid and succinic acid (Comitini et al., 2011). These yeasts also play a role in releasing volatile compounds from non-volatile precursors and increase polysaccharide concentrations in wine (Domizio et al., 2011a; 2011b). Polysaccharides can positively affect wine taste and mouthfeel by increasing the perception of wine 'viscosity' and 'fullness' on the palate (Vidal et al., 2004). Although far less studied, nonSaccharomyces yeast can affect the anthocyanins and colour of wine (Morato et al., 2007; Benito et al., 2011).

The major non-yeast-derived chemical constituents in wine are flavanols (contribute to mouthfeel) and anthocyanins (contribute to wine colour), which are found in grape skins and seeds (Medina et al., 2005). The colour of red wines, which is an important quality factor, is primarily dependent on anthocyanins that accumulate in the grape skin. The concentrations of anthocyanins in grape berry skin vary with grape variety and are affected by viticultural practices and environmental conditions (Downey et al., 2004; Nadal $\&$ Hunter, 2007). The anthocyanin profile of a given grape variety is also linked to its genetic inheritance (Downey et al., 2004).

Pinotage and Cabernet franc grape varieties are cultivated in South Africa as alternative red grape varieties to Cabernet Sauvignon, Syrah and Merlot for the production of red wine. The anthocyanin and flavanol profiles of red wine are known to undergo some modification during winemaking because of physicochemical and biological factors (Chorti et al., 2010; Minnaar \& Booyse, 2011). Considering the biological factors, it is known that the transformation of grape juice into wine is a complex microbial reaction involving the sequential development of various species of yeast responsible for alcoholic fermentation, and lactic acid bacteria responsible for malolactic fermentation. These microbial populations

*Corresponding author: E-mail address: minnaarp@arc.agric.za

Acknowledgements: The authors would like to thank the National Research Foundation of South Africa (Grant no. TP 1207243974), Winetech and the Agricultural Research Council, for financial support 
(yeast and bacteria) potentially can affect the anthocyanin profile of red wine through three distinct processes, viz. anthocyanin adsorption onto cell walls, microbial metabolite-mediated formation of anthocyanin derivatives (acetylated and coumarylated) and anthocyanin hydrolysis. Cell adsorption of anthocyanins is considered a straindependent property within a specific yeast species (Morato et al., 2005; 2007; Mangani et al., 2011), which varies with the polarity of the anthocyanin (Vasserot et al., 1997). During alcoholic fermentation, yeasts release secondary metabolic products such as pyruvic acid and acetaldehyde, which react with anthocyanins to produce more or less stable coloured derivatives such as vitisin A, vitisin B and ethyllinked anthocyanin-flavanol pigments (Medina et al., 2005; Morato et al., 2005; 2007). Anthocyanins and flavanols also contribute to the sensory characteristics of wine, particularly colour and astringency (Caridi et al., 2004). It is known that $S$. cerevisiae wine yeasts are among the contributors to a decrease in the polyphenol concentration in wine (Caridi et al., 2004). The latest technology using non-Saccharomyces yeasts for wine production adds another variable to this topic that requires investigation.

This study investigated the effect of $T$. delbrueckii on the anthocyanins, flavanols and sensorial attributes of Pinotage and Cabernet franc wines.

\section{MATERIALS AND METHODS \\ Grape samples}

Grape samples originated from the Nietvoorbij research farm of the Agricultural Research Council in Stellenbosch. The 2011 Pinotage grapes were obtained from a vineyard on a northern slope in Hutton and Clovelly soil (Soil Classification Working Group, 1991). The scion was grafted onto PI 48 A x Richter 110 (RQ 4) rootstock. The vineyard received drip-irrigation. In 2012 and 2013, Pinotage grapes from another vineyard on the Nietvoorbij farm were used. These grapes were grown on a northern slope in Glenrosa soil. The scion was grafted onto Richter 110 rootstock. The vineyard received drip-irrigation. Cabernet franc grapes were grown on a northern slope in Glenrosa soil. The scion was grafted onto CF 213 x Richter 99 (RY 13 C) rootstock. The vineyard received drip-irrigation.

\section{Yeast treatments}

The two yeast species used for wine production were $T$. delbrueckii [natural isolate strain 654] (Jolly et al., 2003) and $S$. cerevisiae (commercial strain VIN 13, Anchor BioTechnologies, Cape Town, South Africa). Three replicates of each yeast treatment were conducted over three vintages (2011 to 2013). Yeast starter cultures were cultivated in yeast extract-peptone-dextrose broth (Merck, South Africa) in a three-stage procedure, viz. $20 \mathrm{~mL}$ for $12 \mathrm{~h}, 200 \mathrm{~mL}$ for $8 \mathrm{~h}$ and $2 \mathrm{~L}$ for $20 \mathrm{~h}$ in the final stage). Total cell counts were carried out in a Neubauer improved bright-lined counting chamber. Each yeast species was inoculated at a concentration of $1 \mathrm{x}$ $10^{6}$ cells $/ \mathrm{mL}$.

\section{Fermentation conditions}

Cabernet franc and Pinotage grapes were harvested at an average Balling of $25.26^{\circ}$ and $23.47^{\circ}$ respectively, over three consecutive vintages. Wines were made in the Nietvoorbij Research Cellar according to a standardised small-scale winemaking procedure. Grape bunches were mechanically de-stemmed and crushed with the addition of $50 \mathrm{mg} / \mathrm{Kg} \mathrm{SO}_{2}$. The skins and juice were separated and the juice subsequently was transferred to a holding tank for mixing. The juice was divided into equal aliquots and transferred to plastic fermentation bins. The skins were also divided into equal aliquots and added back to the juice to ensure a homogenous matrix. Skin contact occurred for at least an hour before further processing. Di-ammonium hydrogen phosphate (50 $\mathrm{g} / \mathrm{hL}$ DAP) was added after inoculation with $S$. cerevisiae and $T$. delbrueckii. Fermentation with three cap punchdowns per day was allowed to proceed in a temperaturecontrolled room $\left(\mathrm{ca} .25^{\circ} \mathrm{C}\right)$ until the wine reached 0 to $5^{\circ} \mathrm{B}$ total soluble solids (TSS). After this, the juice and skins were separated, pressed in a small balloon press at $200 \mathrm{Kpa}(2$ Bar), and the pressed juice was added back to the free-run juice. The wine was transferred to stainless steel canisters (20 L) equipped with fermentation locks. Wines remained in the $c a .25^{\circ} \mathrm{C}$ controlled rooms for approximately one week until dryness (glucose levels below $2 \mathrm{~g} / \mathrm{L}$ as determined by Clinistix ${ }^{\circledR}$, Bayer, South Africa or digital density meter, DMA 35, Anton Paar, Austria). Malolactic fermentation was not induced for any of the experimental wines. The wines were racked off the yeast lees, their $\mathrm{SO}_{2}$ was adjusted to a total of $85 \mathrm{mg} / \mathrm{L}$ and they were cold stabilised for at least two weeks at $0{ }^{\circ} \mathrm{C}$. The wines were filtered through a 0.45 $\mu \mathrm{m}$ membrane filter and bottled under nitrogen gas. The physicochemical parameters, i.e. residual sugar (glucose and fructose), percentage alcohol, titratable acidity, $\mathrm{pH}$, volatile acidity and glycerol, were measured using a Foss ${ }^{\circledR}$ Winescan (Chemical Laboratory, IWBT, Stellenbosch University, Stellenbosch) five months after bottling.

\section{Sensory analysis}

Sensory analyses were conducted five months after bottling. The tasting panels consisted of seven to twelve judges comprising winemakers and staff who were experienced in wine sensory evaluation. Sensory analysis involved the evaluation of colour intensity, berry/cherry/plum (fruitiness), aroma intensity, body and overall quality for Pinotage and Cabernet franc wines, and herbaceous intensity for the latter. Tasting took place in tasting booths and each judge received ca. $50 \mathrm{~mL}$ of each sample in an international standard wine-tasting glass. The three replicates of each variety/ yeast combination for a given vintage were presented to the judges in random order and each judge received his/her wine in a different order from the other judges. The tasters rated the wine sensory attributes on a $10 \mathrm{~cm}$ unstructured line scale from low to high intensity, thin to full bodied and unacceptable to excellent.

\section{Chemical analysis}

High-performance liquid chromatography-photodiode detection (HPLC-DAD)

High-performance liquid chromatographic detection (HPLCDAD) of anthocyanins and flavanols was performed using a Thermo Separations Products ${ }^{\circledR}$ HPLC, supplied by Spectra System Separation Products. The HPLC was equipped 
with an auto-sampler injecting a $20 \mu \mathrm{L}$ sample. Detection was achieved by means of photodiode array. ChromQuest ${ }^{\mathbb{}}$ software was utilised for data acquisition. Separation was performed at $c a .22{ }^{\circ} \mathrm{C}$, using a polymer reverse phase analytical column (PLRP-S $100 \AA, 5 \mu \mathrm{m}, 250 \times 6.6 \mathrm{~mm}$ ) with polystyrene divinylbenzene as stationary phase. The column was supplied by Polymer Laboratories ${ }^{\circledR}$, USA. Gradient elution with two solvents was used: solvent A consisted of Ortho-phosphoric acid and water $(15: 985 \mathrm{v} / \mathrm{v}, \mathrm{pH}=1.30)$ and solvent B was Ortho-phosphoric acid, acetonitrile and water $(15: 800: 185 \mathrm{v} / \mathrm{v}, \mathrm{pH}=1.35)$. The mobile phase was freshly made up after each run of 20 samples due to the evaporation rate of acetonitrile. The following gradient of eluent was used: $6 \%$ B initially; 6 to $62 \% \mathrm{~B}, 0$ to 86 min.; 62 to $6 \%$ $\mathrm{B}, 86$ to 90 minutes. Reverting to the starting conditions 20 minutes prior to the injection of the next sample resulted in the equilibration of the system. The flow rate was $1 \mathrm{~mL} / \mathrm{min}$. Ultraviolet visible spectra were recorded for all compounds. The analytical method was based on the method described by Waterhouse et al. (1999) for grape and wine polyphenol separation and quantification. Anthocyanins were detected at $520 \mathrm{~nm}$ using malvidin 3-ß-glucopyranoside as external standard, and flavanols were detected at $280 \mathrm{~nm}$ using $(+)$-catechin as external standard. The identification of the polyphenol compounds was confirmed by their relative retention times and UV-visible absorption characteristics (Waterhouse et al., 1999; De Villiers et al., 2011). Samples for each of the treatments were taken from three separate bottles of the same treatment (triplicate). Samples were analysed separately. Results were recorded from calibration curves, retention times and spectral data and expressed as $\mathrm{mg} / \mathrm{L}$.

\section{Statistical analysis}

The chemical and sensorial data was analysed using XLSTAT 2010 (add-on statistical software for Excel version 7.5.2, 2010). Data from the analysed wines (chemical and sensorial) was subjected to analysis of variance (ANOVA) to ascertain the effects of yeast treatment on the physicochemical parameters, polyphenol compounds and sensory attributes to establish if identified factors or interactions affected variables in the experiment. Data from the analysed wines was also subjected to multivariate analysis, i.e. principal component analysis, to establish clustering of the variables and their interrelationships to the wine and treatments (yeast strains).

\section{RESULTS AND DISCUSSION}

Physicochemical and fermentation parameters measured in Pinotage and Cabernet franc must and wines

The Pinotage and Cabernet franc grape must sugar averages in ${ }^{\circ} \mathrm{B}$ over three years were slightly different prior to inoculation (Table 1). Cabernet franc grape must was approximately $2{ }^{\circ} \mathrm{B}$ higher in total soluble solids. This was reflected in differences in alcohol concentration of $13 \%$ for Pinotage and $15 \%$ for Cabernet franc wines.

Titratable acidity was higher in the Pinotage grape must compared to the Cabernet franc grape must, while the average $\mathrm{pH}$ values were similar for both grape varieties over three vintages (Table 1). Considering the expected variability between vintages within a grape variety, the analyses of the base musts in terms of physicochemical parameters were of sufficient similarity per variety to make comparisons.

Monitoring of the fermentations by measuring degrees Balling showed that the T. delbrueckii treatments took the same or double the time to ferment to below $0{ }^{\circ} \mathrm{B}$ compared to those of the S. cerevisiae treatments (data not shown). This is to be expected, as it is known that the T. delbrueckii yeasts are slower fermenters than S. cerevisiae yeasts. However, the separation of skins from the wine post-fermentation was at the same time for each grape variety, with the exception of 2013 Cabernet franc, for which the T. delbrueckii were on the skins for six days longer. This ensured that the skin contact time and therefore anthocyanin and flavanol extraction was the same for a specific yeast treatment. The Pinotage wines were on the skins for a shorter time (five to seven days) than the Cabernet franc wines (seven to 14 days).

The volatile acidity concentrations of the wines were

\section{TABLE 1}

Physicochemical parameters measured in Pinotage and Cabernet franc grape must and wine indicating average values over three consecutive vintages (2011/2012/2013) and standard deviations. Wines were produced on a small scale with different yeasts.

\begin{tabular}{|c|c|c|c|c|}
\hline \multirow[b]{2}{*}{$\begin{array}{l}\text { Parameters }^{1} \\
\text { measured }\end{array}$} & \multicolumn{2}{|c|}{ Pinotage must/wine } & \multicolumn{2}{|c|}{ Cabernet franc must/wine } \\
\hline & $\begin{array}{l}\text { S. cerevisiae } \\
\text { strain VIN } 13\end{array}$ & $\begin{array}{l}\text { T. delbrueckii } \\
\text { strain } 654\end{array}$ & $\begin{array}{l}\text { S. cerevisiae } \\
\text { strain VIN } 13\end{array}$ & $\begin{array}{l}\text { T. delbrueckii } \\
\text { strain } 654\end{array}$ \\
\hline Base must $\left({ }^{\circ} \mathrm{B}\right)^{2}$ & \multicolumn{2}{|c|}{$23.47( \pm 1.97)^{3}$} & \multicolumn{2}{|c|}{$25.26( \pm 0.73)$} \\
\hline $\mathrm{TA}^{4}(\mathrm{~g} / \mathrm{L})^{5}$ & \multicolumn{2}{|c|}{$6.66( \pm 0.36)$} & \multicolumn{2}{|c|}{$5.33( \pm 1.01)$} \\
\hline $\mathrm{pH}$ & \multicolumn{2}{|c|}{$3.36( \pm 0.13)$} & \multicolumn{2}{|c|}{$3.52( \pm 0.17)$} \\
\hline Volatile acidity $(\mathrm{g} / \mathrm{L})$ & $0.41( \pm 0.13)$ & $0.41( \pm 0.15)$ & $0.37( \pm 0.21)$ & $0.48( \pm 0.22)$ \\
\hline Glucose $(\mathrm{g} / \mathrm{L})$ & $0.33( \pm 0.16)$ & $0.52( \pm 0.27)$ & $0.43( \pm 0.18)$ & $1.04( \pm 0.49)$ \\
\hline Fructose $(\mathrm{g} / \mathrm{L})$ & $1.11( \pm 0.33)$ & $1.09( \pm 0.32)$ & $1.22( \pm 0.08)$ & $2.28( \pm 0.31)$ \\
\hline Fructose/glucose $(\mathrm{g} / \mathrm{L})$ & $1.32( \pm 0.41)$ & $1.61( \pm 0.60)$ & $1.60( \pm 0.19)$ & $2.96( \pm 0.42)$ \\
\hline Alcohol (v/v \%) & $13.64( \pm 1.76)$ & $13.53( \pm 1.81)$ & $15.34( \pm 0.51)$ & $15.15( \pm 0.52)$ \\
\hline Glycerol (g/L) & $9.76( \pm 4.89)$ & $9.67( \pm 1.17)$ & $10.05( \pm 0.41)$ & $11.03( \pm 0.52)$ \\
\hline
\end{tabular}

${ }^{1}$ Analyses done by Foss ${ }^{\circledR}$ Winescan (Chemical Laboratory, IWBT, Stellenbosch University, Stellenbosch); ${ }^{\circ} \mathrm{B}=$ Degrees Balling; ${ }^{3}=$ Standard deviation; ${ }^{4} \mathrm{TA}=$ Titratable acidity; ${ }^{5} \mathrm{~g} / \mathrm{L}=$ Grams per litre 
similar (Table 1), except for Cabernet franc fermented with $T$. delbrueckii. Glycerol concentrations for both grape varieties were above $5.2 \mathrm{~g} / \mathrm{L}$ (Table 1). This is the level where a sweet taste can be detected (Noble \& Bursick, 1984). Cabernet franc wines were highest in glycerol levels. Glycerol can also contribute to smoothness (mouthfeel) and complexity in wines (Scanes et al., 1998; Prior et al., 2000; Ciani \& Comitini, 2011).

\section{Principal component analysis using physicochemical parameters}

Principal component analysis was applied to the physicochemical parameters to determine differences and similarities (relationships) between Cabernet franc and Pinotage wines fermented with the two different yeast species.

\section{Pinotage wines}

Principal component analysis (Fig. 1a) for physicochemical variables was applied to the percentage in weight of each parameter in relation to the total number of physicochemical parameters. Principal component analysis explained $74.90 \%$ of the total variance in the data through the first two dimensions, with $47.14 \%$ and $27.76 \%$ explained by PCA 1 and PCA 2 respectively.

Pinotage wines inoculated with $S$. cerevisiae was high in fructose and lactic acid for the 2012 vintage. Wines made with $T$. delbrueckii during 2012 were high in glycerol, $\mathrm{pH}$ and volatile acidity. Pinotage wines made with $T$. delbrueckii during 2013 were high in glucose and malic acid. Pinotage wines made with $S$. cerevisiae during 2013 clustered together with wines made with $T$. delbrueckii. Wines made during 2011 with both yeasts were low in all physicochemical parameters compared to wines made during 2012 and 2013
This could be attributed to the fact that the grapes harvested during 2011 originated from a different vineyard.

\section{Cabernet franc wines}

Principal component analysis (Fig. 1b) for physicochemical variables was applied to the percentage in weight of each parameter in relation to the total number of physicochemical parameters. Principal component analysis explained 83.57\% of the total variance in the data through the first two dimensions, with $46.20 \%$ and $37.37 \%$ explained by PCA 1 and PCA 2 respectively.

Cabernet franc wines inoculated with $T$. delbrueckii was higher in glycerol, lactic acid, glucose, malic acid, fructose and titratable acidity compared to Cabernet franc grape must inoculated with the $S$. cerevisiae yeast. Percentage alcohol, volatile acidity and $\mathrm{pH}$ were highest in wines made with $S$. cerevisiae. There was a positive relationship (increases together) between wines made with $T$. delbrueckii and increased concentrations of physicochemical parameters measured.

\section{Sensory attributes measured in Cabernet franc and Pinotage wines}

Cabernet franc grape must inoculated with both $S$. cerevisiae and $T$. delbrueckii yeasts showed similar scores in wine colour intensity (Table 2). Pinotage grape must inoculated with $T$. delbrueckii was higher in colour intensity compared to Pinotage grape must inoculated with $S$. cerevisiae. However, Pinotage samples showed a notably greater standard deviation compared to Cabernet franc samples.

The differences in sugar and glycerol levels between the two grape varieties (Table 2) are evident, but these parameters do not sufficiently explain the differences observed between mouthfeel and overall quality. Differences in berry attributes

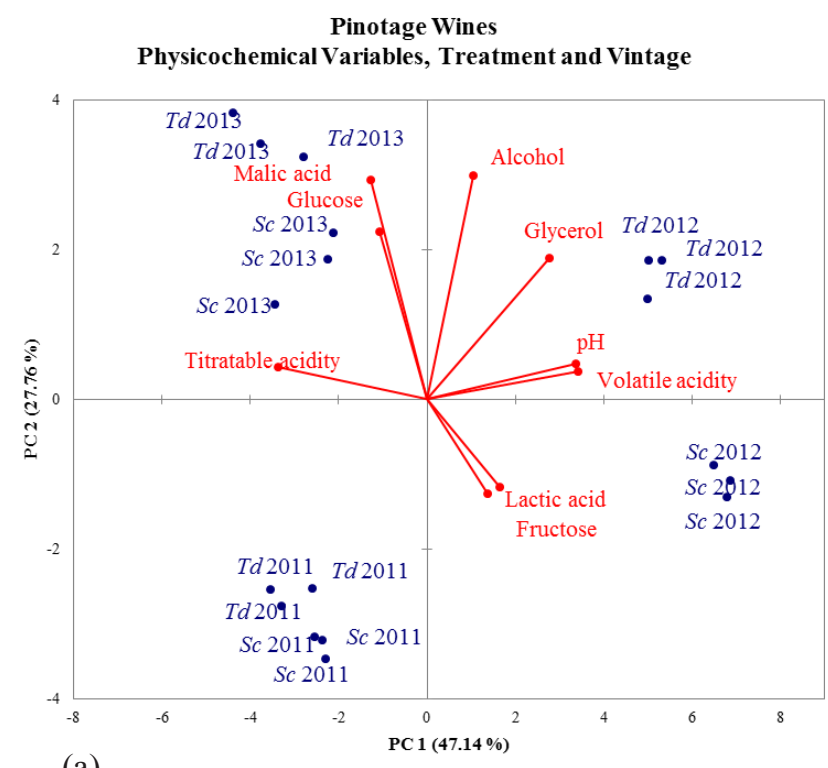

(a)

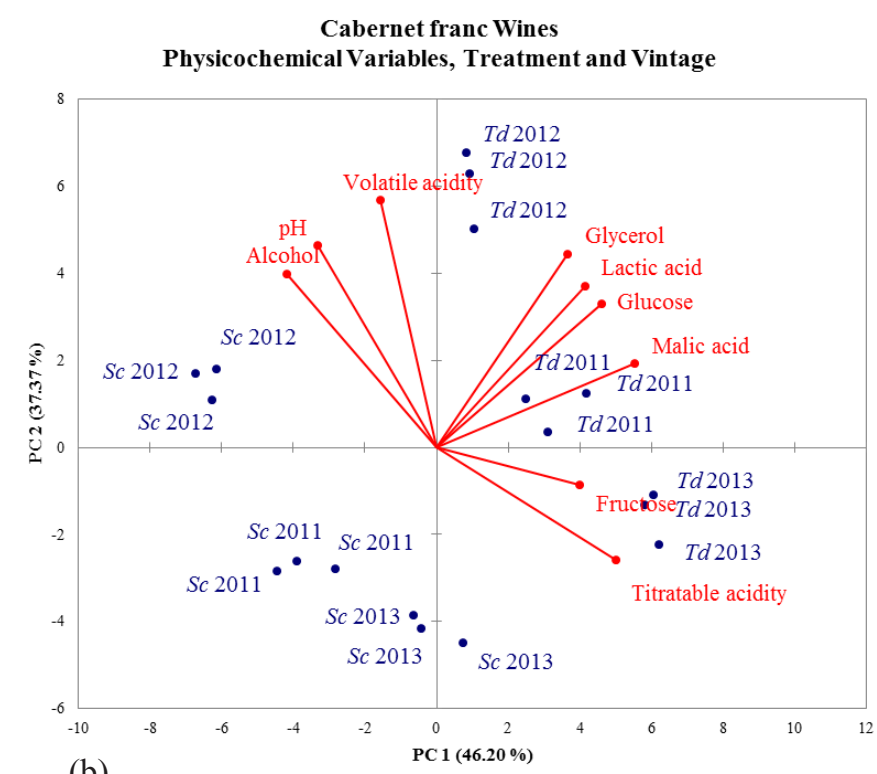

(b)

\section{FIGURE}

Principal component analysis bi-plots of nine physicochemical variables in relation to treatment (yeast) and vintage for Pinotage (a) and Cabernet franc (b) wines made from grapes harvested at an average of $23.47^{\circ} \mathrm{B}$ and $25.26^{\circ} \mathrm{B}$ respectively. $S_{c}=$ Saccharomyces cerevisiae $; \mathrm{Td}=$ Torulaspora delbrueckii. 
for both the grape varieties and herbaceous for Cabernet franc only were noted between the two treatments. Pinotage wines subjected to the two treatments showed notable differences in colour, berry, mouthfeel and overall quality attributes.

\section{Analysis of variance using sensory attributes}

Wine sensory attribute data was analysed using analysis of variance to establish significant differences between yeast treatments within a specific grape variety (Table 3 ). Pinotage grape must inoculated with $T$. delbrueckii scored higher in colour intensity compared to Pinotage grape must inoculated with $S$. cerevisiae.

Cabernet franc grape must inoculated with T. delbrueckii scored higher in fruitiness and mouth feel properties compared to Cabernet franc inoculated with $S$. cerevisiae. Significant differences between treatments were evident for both grape varieties. Table 3 lists the comparative scores in percentage for wine treatment, grape varieties and selected sensory attributes. The listed data was generated by the application of univariate analysis.

\section{Principal component analysis using sensory attribute scores}

Principal component analysis was applied to the sensory score data to establish differences and similarities (relationships) between treatments. attribute in relation to the total number of attributes. Principal component analysis explained $96.24 \%$ of the total variance in the data through the first two dimensions, with $92.18 \%$ and $4.06 \%$ explained by PCA 1 and PCA 2 respectively.

Pinotage grape must inoculated with both yeast species did not form separate clusters in the PCA plot (Fig. 2a). However, colour intensity and fruitiness, and overall quality and mouthfeel, formed a cluster for both treatments. Pinotage wines produced by the two yeast species therefore could not be differentiated from one another based on the sensory attribute.

\section{Cabernet franc wines}

Principal component analysis for sensory attribute variables (Fig. 2b) was applied to the percentage in weight of each attribute in relation to the total number of attributes. Principal component analysis explained $97.79 \%$ of the total variance in the data through the first two dimensions, with $92.34 \%$ and $5.45 \%$ explained by PCA 1 and PCA 2 respectively.

Overall quality, mouthfeel and fruitiness scored highest in Cabernet franc wines made with $T$. delbrueckii yeasts in the 2011 harvest. However, Cabernet franc wines made during 2011 from S. cerevisiae yeasts scored highest in colour intensity. Wines made with both yeast species from grapes harvested during 2012 and 2013 were lowest in all attributes.

\section{Pinotage wines}

Principal component analysis for sensory attribute variables (Fig. 2a) was applied to the percentage in weight of each

TABLE 2

Average scores of sensory attributes in percentage measured in Pinotage (2011/2012/2013) and Cabernet franc (2011/2012/2013) wines. Wines produced on a small scale with different yeasts.

\begin{tabular}{lllll}
\hline & \multicolumn{2}{c}{ Pinotage wines } & \multicolumn{2}{c}{ Cabernet franc wines } \\
\cline { 2 - 5 } Attributes $^{1}$ & $\begin{array}{l}\text { S. cerevisiae } \\
\text { strain VIN 13 }\end{array}$ & $\begin{array}{l}\text { T. delbrueckii } \\
\text { strain } \mathbf{6 5 4}\end{array}$ & $\begin{array}{l}\text { S. cerevisiae } \\
\text { strain VIN 13 }\end{array}$ & $\begin{array}{l}\text { T. delbrueckii } \\
\text { strain 654 }\end{array}$ \\
\hline Colour intensity & $44.24( \pm 17.43)$ & $55.33( \pm 13.86)$ & $54.33( \pm 5.50)$ & $55.33( \pm 6.70)$ \\
Berry & $45.33( \pm 9.01)$ & $52.01( \pm 11.13)$ & $48.01( \pm 5.29)$ & $55.33( \pm 11.15)$ \\
Herbaceous & $\mathrm{NA}^{2}$ & $\mathrm{NA}$ & $39.11( \pm 8.00)$ & $36.51( \pm 5.51)$ \\
Mouthfeel & $42.33( \pm 7.09)$ & $45.66( \pm 8.51)$ & $47.66( \pm 4.04)$ & $51.33( \pm 8.73)$ \\
Overall quality & $40.66( \pm 7.37)$ & $45.66( \pm 7.37)$ & $48.33( \pm 5.13)$ & $53.66( \pm 10.78)$ \\
\hline
\end{tabular}

${ }^{1}$ As evaluated on a $10 \mathrm{~cm}$ unstructured line scale from low to high intensity, thin to full bodied and unacceptable to excellent.; ${ }^{2} \mathrm{NA}=\mathrm{Not}$ applicable

TABLE 3

Comparison of four sensory attributes between treatments for Pinotage and Cabernet franc wines fermented with two yeast species.

\begin{tabular}{lllll}
\hline \multirow{2}{*}{$\begin{array}{l}\text { Sensory } \\
\text { attributes }\end{array}$} & \multicolumn{2}{c}{ Pinotage wines $(\boldsymbol{n}=\mathbf{1 8})$} & \multicolumn{2}{c}{ Cabernet franc wines $(\boldsymbol{n}=\mathbf{1 8})$} \\
\cline { 2 - 5 } & $\begin{array}{l}\text { S. cerevisiae } \\
\text { VIN 13 }\end{array}$ & $\begin{array}{l}\text { T. delbrueckii } \\
\text { strain } \mathbf{6 5 4}\end{array}$ & $\begin{array}{c}\text { S. cerevisiae } \\
\text { VIN 13 }\end{array}$ & $\begin{array}{l}\text { T. delbrueckii } \\
\text { strain 654 }\end{array}$ \\
\hline Colour intensity & $45.72^{\mathrm{b}^{*}}$ & $54.63^{\mathrm{a}}$ & $54.15^{\mathrm{a}}$ & $55.23^{\mathrm{a}}$ \\
Fruitiness & $47.46^{\mathrm{b}}$ & $52.85^{\mathrm{a}}$ & $48.42^{\mathrm{b}}$ & $54.95^{\mathrm{a}}$ \\
Mouthfeel & $43.75^{\mathrm{a}}$ & $46.04^{\mathrm{b}}$ & $47.32^{\mathrm{b}}$ & $51.69^{\mathrm{a}}$ \\
Overall quality & $42.71^{\mathrm{b}}$ & $46.87^{\mathrm{a}}$ & $48.58^{\mathrm{a}}$ & $52.13^{\mathrm{a}}$ \\
\hline
\end{tabular}

${ }^{*}$ Different superscripts $(\mathrm{a}, \mathrm{b})$ on the same line indicate significant differences in the parameters among the different treatments according to ANOVA $(p<0.05)$. 
Pinotage Wines

Sensory Attributes, Treatment and Vintage

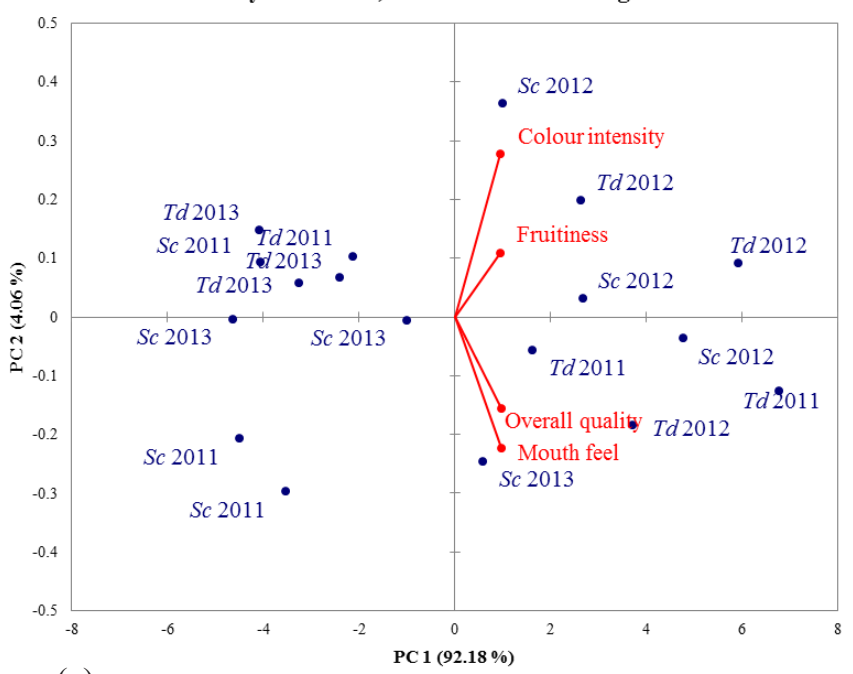

(a)

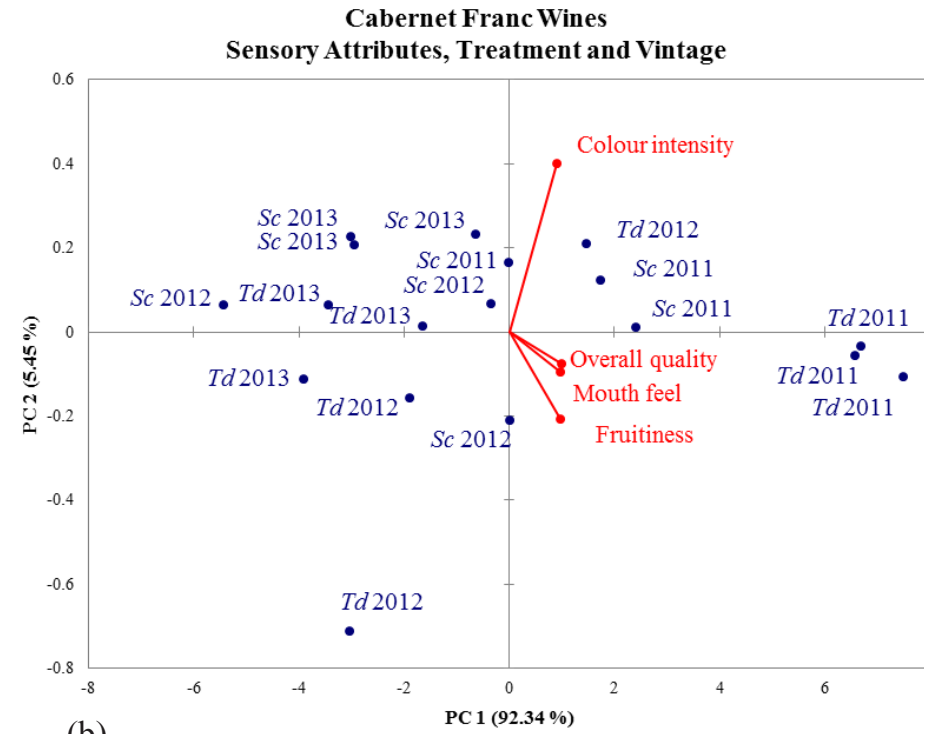

(b)

FIGURE 2

Principal component analysis bi-plots of four sensory attribute variables in relation to treatment (yeast) and vintage for Pinotage (a) and Cabernet franc (b) wines made from grapes harvested at an average of $23.47^{\circ} \mathrm{B}$ and $25.26^{\circ} \mathrm{B}$ respectively. Sc $=$ Saccharomyces cerevisiae; $T d=$ Torulaspora delbrueckii.

Polyphenol concentrations measured in Pinotage and Cabernet franc wines

Analysis of variance using anthocyanin and flavanol data Wine polyphenol variables were analysed using ANOVA to determine the effect of treatment on the anthocyanin and flavanol concentration differences of Cabernet franc and Pinotage wines made with $S$. cerevisiae and $T$. delbrueckii respectively.

Anthocyanins and flavanols measured in Pinotage wines (Table 4) made with $T$. delbrueckii were consistently higher compared to those in Pinotage grape must inoculated with S. cerevisiae. Glycosylated anthocyanins and acetylated anthocyanins were highest in Pinotage wines made with T. delbrueckii. Coumarylated anthocyanin concentrations were similar in concentration for both Pinotage wines. However, differences in flavanol concentration were observed between the treatments.

Cabernet franc wines made with $S$. cerevisiae were higher in anthocyanin and flavanol concentrations compared to Cabernet franc wines made with T. delbrueckii (Table 4). Glycosylated anthocyanins were higher in Cabernet franc wines made with $S$. cerevisiae compared to Cabernet franc wines made with $T$. delbrueckii. Acylated and coumarylated anthocyanins were slightly higher in Cabernet franc wines made with $S$. cerevisiae yeasts compared to $T$. delbrueckii wines, except for malvidin 3-(6-acetyl) glucoside and petunidin 3-(6-acetyl) glucoside, which were lower in Cabernet franc wines made with $S$. cerevisiae. The concentrations of procyanidin B2, epigallocatechin gallate and epicatechin gallate were higher in Cabernet franc wines made with $S$. cerevisiae than in Cabernet franc wines made with $T$. delbrueckii.

Table 4 lists the average polyphenol concentrations (variables) for Pinotage and Cabernet franc wines made with two yeast species. Significant differences were evident between yeast species within a grape variety. Significant differences between treatments were observed for all variables except malvidin 3-(6-p-coumaroyl) glucoside and delphinidin 3-(6-p-coumaroyl) glucoside in both grape varieties.

\section{Principal component analysis using anthocyanin and flavanol data}

Principal component analysis was applied to the anthocyanin and flavanol data to determine differences and similarities (associations) between treatments of Pinotage and Cabernet franc wines. Figs $3 a$ and $3 b$ depict the anthocyanin and flavanol compositional variables of Cabernet franc and Pinotage wines for principal component analysis. Table 5 lists the abbreviations and explanations used in Figs $3 \mathrm{a}$ and $\mathrm{b}$ of the PCA bi-plots.

\section{Pinotage wines}

Principal component analysis (Fig. 3a) for flavonoid variables was applied to the percentage in weight of each compound in relation to the total number of flavonoids. Principal component analysis explained $84.18 \%$ of the total variance in the data through the first two dimensions, with $69.71 \%$ and $14.47 \%$ explained by PCA 1 and PCA 2 respectively.

Clustering occurred in both PCA 1 and PCA 2. Pinotage wines made with $T$. delbrueckii in the 2011 and 2012 vintages grouped together. Wines made with $T$. delbrueckii in 2013, however, formed a separate group that was high in petunidin 3-(6-p-coumaroyl) glucoside. Wines of the 2011 and 2012 vintages showed higher concentrations of epigallocatechin gallate, procyanidin B2, epicatechin gallate, peonidin 3-O-glucoside, delphinidin 3-(6-acetyl) glucoside and malvidin 3-O-glucoside compared to wines made with $S$. cerevisiae from grapes harvested in the same vintages. Wines of the 2013 vintage were highest in peonidin 
TABLE 4

Pinotage and Cabernet franc wine variables (flavonoids) including significant differences (superscript), showing effect of yeast species treatment on anthocyanins (colour) and flavanols (mouthfeel). Results represent data collected over three consecutive vintages.

\begin{tabular}{lllll|}
\hline & \multicolumn{2}{c}{ Pinotage wine } & \multicolumn{2}{c}{ Cabernet franc wine } \\
\cline { 2 - 5 } Polyphenol compounds & $\begin{array}{l}{ }^{1} \text { S. cerevisiae } \\
\text { strain VIN 13 }\end{array}$ & $\begin{array}{l}{ }^{2} \text { T. delbrueckii } \\
\text { strain 654 }\end{array}$ & $\begin{array}{l}\text { S. cerevisiae } \\
\text { strain VIN 13 }\end{array}$ & $\begin{array}{l}\text { T. delbrueckii } \\
\text { strain 654 }\end{array}$ \\
\hline Cyanidin 3-O- Gluc ${ }^{3}$ & $1.631^{\mathrm{b}^{\mathrm{b}}}$ & $3.719^{\mathrm{a}}$ & $4.632^{\mathrm{c}}$ & $2.672^{\mathrm{d}}$ \\
Petunidin 3-O- Gluc & $2.823^{\mathrm{b}}$ & $3.202^{\mathrm{a}}$ & $6.372^{\mathrm{c}}$ & $4.226^{\mathrm{d}}$ \\
Peonidin 3-O- Gluc & $1.290^{\mathrm{b}}$ & $3.352^{\mathrm{a}}$ & $3.756^{\mathrm{a}}$ & $2.552^{\mathrm{c}}$ \\
Malvidin 3-O- Gluc & $37.931^{\mathrm{b}}$ & $62.171^{\mathrm{a}}$ & $52.339^{\mathrm{c}}$ & $38.824^{\mathrm{b}}$ \\
Delphinidin 3-(6-acetyl) Gluc & $3.413^{\mathrm{b}}$ & $4.360^{\mathrm{a}}$ & $5.706^{\mathrm{c}}$ & $3.399^{\mathrm{b}}$ \\
Petunidin 3-(6-acetyl) Gluc & $1.416^{\mathrm{b}}$ & $3.623^{\mathrm{a}}$ & $2.627^{\mathrm{c}}$ & $3.386^{\mathrm{a}}$ \\
Peonidin 3-(6-acetyl) Gluc & $2.356^{\mathrm{b}}$ & $3.212^{\mathrm{a}}$ & $2.567^{\mathrm{b}}$ & $2.198^{\mathrm{c}}$ \\
Malvidin 3-(6-acetyl) Gluc & $34.562^{\mathrm{b}}$ & $50.561^{\mathrm{a}}$ & $42.864^{\mathrm{c}}$ & $14.203^{\mathrm{d}}$ \\
Delphinidin 3-(6- $p$-coum ${ }^{4}$ Gluc & $1.439^{\mathrm{a}}$ & $1.477^{\mathrm{a}}$ & $0.774^{\mathrm{b}}$ & $0.691^{\mathrm{b}}$ \\
Petunidin 3-(6- $p$-coum) Gluc & $1.782^{\mathrm{b}}$ & $2.024^{\mathrm{a}}$ & $1.142^{\mathrm{c}}$ & $0.852^{\mathrm{d}}$ \\
Malvidin 3-(6- $p$-coum) Gluc & $14.001^{\mathrm{a}}$ & $14.332^{\mathrm{a}}$ & $4.922^{\mathrm{b}}$ & $4.153^{\mathrm{b}}$ \\
Procyanidin B2 & $76.831^{\mathrm{b}}$ & $158.832^{\mathrm{a}}$ & $144.861^{\mathrm{c}}$ & $99.118^{\mathrm{d}}$ \\
EGCG5 & $5.140^{\mathrm{b}}$ & $10.695^{\mathrm{a}}$ & $8.598^{\mathrm{c}}$ & $6.163^{\mathrm{d}}$ \\
Epicatechin gallate & $7.732^{\mathrm{b}}$ & $11.122^{\mathrm{a}}$ & $7.623^{\mathrm{b}}$ & $7.066^{\mathrm{c}}$ \\
\hline
\end{tabular}

${ }^{1} S=$ Saccharomyces $;{ }^{2} T=$ Torulaspora $;{ }^{3}$ Gluc $=$ glucoside $;{ }^{4}$ Coum $=$ coumaroyl; ${ }^{5} \mathrm{EGCG}=$ epigallocatechin gallate; ${ }^{*}$ Different superscripts $(\mathrm{a}, \mathrm{b}, \mathrm{c}, \mathrm{d})$ on the same line indicate significant differences in the parameters among the different treatments according to ANOVA $(p<0.05)$.

Pinotage Wines

Polyphenol Variables, Treatment and Vintage

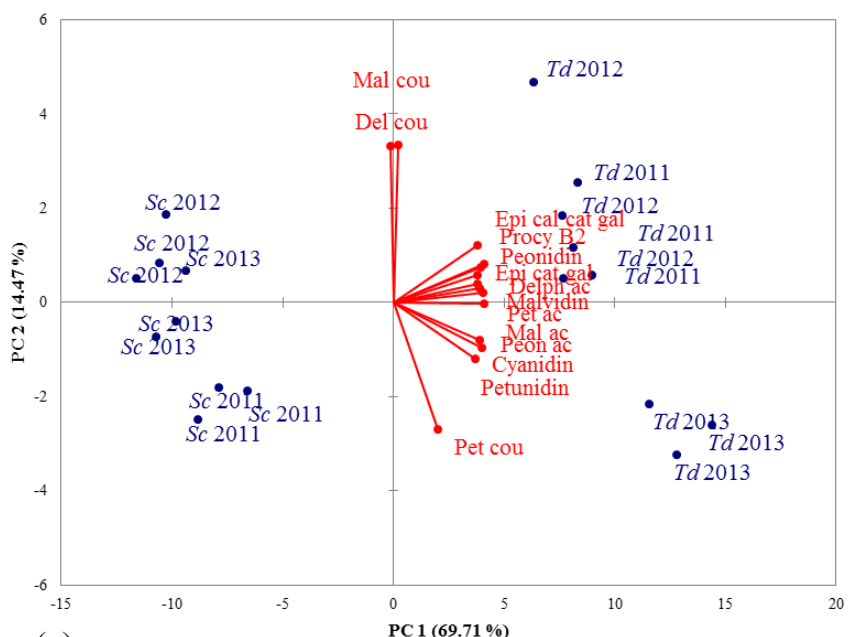

(a)
Cabernet franc Wines Polyphenol Variables, Treatment and Vintage

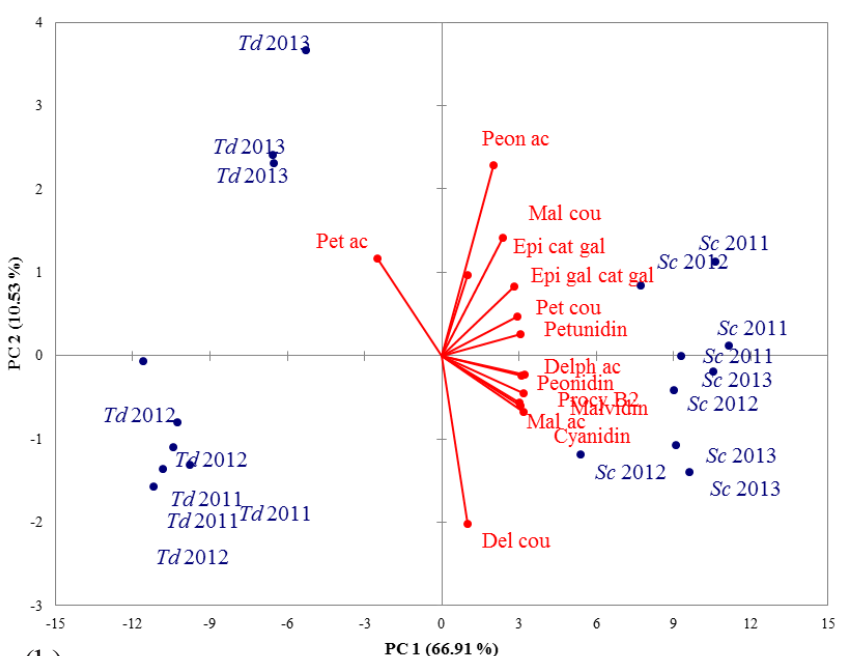

(b)

FIGURE 3

Principal component analysis bi-plots of 14 flavonoid variables in relation to treatment (yeast) and vintage for Pinotage (a) and Cabernet franc (b) wines made from grapes harvested at an average of $23.47^{\circ} \mathrm{B}$ and $25.26^{\circ} \mathrm{B}$ respectively. $S c=S a c c h a r o m y c e s$ cerevisiae; $T d=$ Torulaspora delbrueckii.

3-(6-acetyl) glucoside, cyanidin 3-O-glucoside and petunidin 3-O-glucoside.

\section{Cabernet franc wines}

Principal component analysis (Fig. 3b) for flavonoid variables was applied to the percentage in weight of each compound in relation to the total number of flavonoids. Principal component analysis explained $77.44 \%$ of the total variance in the data in the first two dimensions, with $66.91 \%$ and $10.53 \%$ explained by PCA 1 and PCA 2 respectively. Separation occurred in both PCA 1 and PCA 2.

Cabernet franc wines (Fig. 3b) made with $S$. cerevisiae from grapes harvested during 2011, 2012 and 2013 grouped together. Wines from these vintages showed the highest concentrations of epicatechin gallate, epigallocatechin gallate, malvidin 3-(6-p-coumaroyl) glucoside, petunidin 
TABLE 5

Explanations of abbreviations for variables used in Figs $3 a$ and $3 b$.

\begin{tabular}{llll}
\hline Abbreviation & Explanation & Abbreviation & Explanation \\
\hline Cyanidin & Cyanidin 3-O-glucoside & Peon ac & Peonidin 3-(6-acetyl) glucoside \\
Delp ac & Delphinidin 3-(6-acetyl) glucoside & Petunidin & Petunidin 3- $O$-glucoside \\
Del cou & Delphinidin 3-(6- $p$-coumaroyl) glucoside & Pet ac & Petunidin 3-(6-acetyl) glucoside \\
Malvidin & Malvidin 3- $O$-glucoside & Pet cou & Petunidin 3-(6- $p$-coumaroyl) glucoside \\
Mal ac & Malvidin 3-(6-acetyl) glucoside & Epi cat gal & Epicatechin gallate \\
Mal cou & Malvidin 3-(6- $p$-coumaroyl) glucoside & Epi gal cat gal & Epigallocatechin gallate \\
Peonidin & Peonidin 3- $O$-glucoside & Procy B2 & Procyanidin B2 \\
\hline
\end{tabular}

3-(6- $p$-coumaroyl) glucoside and petunidin 3-O-glucoside. A second cluster formed with delphinidin 3-(6-acetyl) glucoside, peonidin 3-O-glucoside, malvidin 3-O-glucoside, procyanidin B2, malvidin 3-(6-acetyl) glucoside, cyanidin 3-O-glucoside and procyanidin B2 in Cabernet franc wines made with $S$. cerevisiae.

Cabernet franc wines made with $T$. delbrueckii were low in all the above-mentioned variables, except for petunidin 3-(6-acetyl) glucoside, which was highest in Cabernet franc wines made with $T$. delbrueckii of grapes harvested during 2013. Delphinidin 3-(6-p-coumaroyl) glucoside was highest in Cabernet franc wines made with both $S$. cerevisiae and $T$. delbrueckii yeasts.

\section{CONCLUSIONS}

Pinotage grape must inoculated with $T$. delbrueckii (strain 654) scored highest in colour intensity (anthocyanins) and mouthfeel (flavanols). Flavonoids measured in the wines made from $S$. cerevisiae from the 2013 vintage formed a separate cluster on the PCA bi-plots from the 2011/2012 cluster. The separate cluster of variables that formed can be ascribed to vintage effect. Sensory analysis revealed notable differences for both grape variety and yeast treatment, except for colour attributes for Cabernet franc wines. Alcohol content for both grape varieties (wines) showed similar percentages for both treatments, whereas the glucose/fructose residual levels were different for both grape varieties and treatments. Pinotage wines made with $T$. delbrueckii showed improved colour intensity compared to Cabernet franc wines made with $T$. delbrueckii. However, overall quality scored highest for Cabernet franc wines made with $T$. delbrueckii (strain 654).

Cabernet franc wines made with $S$. cerevisiae (strain VIN 13) were higher in colour intensity and mouthfeel than Cabernet franc wines made with $T$. delbrueckii (strain 654). This was apparent for the data over all three vintages, even though the wines, when analysed, were not of the same age and some degree of polymerisation had occurred. Significant differences in chemical, physicochemical and sensory data for both grape varieties and treatments were evident in the data.

The sensory attribute scores for Pinotage wines correlated with the anthocyanin and flavanol concentrations. Cabernet franc wines, however, showed a negative correlation between sensory attribute scores and anthocyanin and flavanol concentrations. Flavonols and phenolic acids in both Pinotage and Cabernet franc wines will be quantified in a follow-up investigation. There were clear differences in sensory scores, polyphenol and physicochemical parameters of Pinotage and Cabernet franc wines made with $S$. cerevisiae and T. delbrueckii yeasts. In this study, only one strain of each yeast species was used. It can be expected that a similar trend may be observed for other strains. However, due to the high genetic variability found amongst yeast strains within a species, this observation will have to be substantiated with further research.

In conclusion, Pinotage and Cabernet franc grape varieties reacted to both treatments. It is clear from the analysis of variance and principal component analysis that T. delbrueckii (strain 654) is the preferred yeast for Pinotage grape must, and S. cerevisiae (strain VIN 13) the preferred yeast for Cabernet franc grape must in terms of anthocyanin (colour) and flavanol (mouthfeel) concentration.

\section{LITERATURE CITED}

Benito, S., Morato, A., Palomero, F., Gonzalez, M.C. \& Suarez-Lepe, J.A., 2011. Formation of vinylphenolic pyranoanthocyanins by Saccharomyces cerevisiae and Pichia guilliermondii in red wines produced following different fermentation strategies. Food Chem. 124, 15-23.

Caridi, A., Cufari, A., Lovino, R., Palumbo, R. \& Tedesco, I., 2004. Influence of yeast on polyphenol composition of wine. Food Tech. Biotech. 42, 37-40.

Chorti, E., Guidoni, S., Ferrandino, A. \& Novello, V., 2010. Effect of different cluster sunlight exposure levels on ripening and anthocyanin accumulation in Nebbiolo grapes. Am. J. Enol. Vitic. 61, 23-30.

Ciani, M. \& Comitini, F., 2011. Non-Saccharomyces wine yeasts have a promising role in biotechnological approaches to winemaking. Ann. Microbiol. 61, 25-32.

Comitini, F., Gobbi, M., Domizio, P., Romani, C., Lencioni, L., Mannazzu, I. \& Ciani, M., 2011. Selected non-Saccharomyces wine yeasts in controlled multistarter fermentations with Saccharomyces cerevisiae. Food Microbiol. 28, 273-882.

De Villiers, A.J., Cabooter, D., Lynen, F., Desmet, G. \& Sandra, P., 2011. High-efficiency performance liquid chromatographic analysis of red wine anthocyanins. J. Chrom. A. 1218, 4660-4670.

Domizio, P., Romani, C., Comitini, F., Gobbi, M., Lencioni, L., Mannazzu, I. \& Ciani, M., 2011a. Potential spoilage non-Saccharomyces yeasts in mixed cultures with Saccharomyces cerevisiae. Ann. Microbiol. 61, $137-$ 144

Domizio, P., Romani, C., Lencioni, L., Comitini, F., Gobbi, M., Mannazzu, I. \& Ciani, M., 2011b. Outlining a future for non-Saccharomyces yeasts: Selection of putative spoilage wine strains to be used in association with Saccharomyces cerevisiae for grape juice fermentation. Int. J. Food Microbiol. 147, 170-180 
Downey, M.O., Harvey, J.S. \& Robinson, S.P., 2004. The effect of bunch shading on berry development and flavonoid accumulation in Shiraz grapes. Aust. J. Grape Wine Res. 10, 55-73.

Jolly, N.P., Augustyn, O.P.H. \& Pretorius, I.S., 2003. The occurrence of nonSaccharomyces yeast strains over three vintages in four vineyards and grape musts from four production regions of the Western Cape, South Africa. S. Afr. J. Enol. Vitic. 24, 35-42.

Jolly, N.P., Augustyn, O.P.H. \& Pretorius, I.S., 2006. The role and use of non-Saccharomyces yeasts in wine production. S. Afr. J. Enol. Vitic. 27, 15-39.

Jolly, N.P., Valera, C. \& Pretorius, I.S., 2014. Not your ordinary yeast: NonSaccharomyces yeasts in wine production uncovered. FEMS Yeast Res. 14, 215-237.

Mangani, S., Buscioni, G., Collina, L., Bocci, E. \& Vincenzini, M., 2011. Effects of microbial populations on anthocyanin profile of Sangiovese wines produced in Tuscany, Italy. Am. J. Enol. Vitic. 62, 487-494.

Medina, K., Boido, E., Dellacassa, E. \& Carrau, F., 2005. Yeast interactions with anthocyanins during red wine fermentation. Am. J. Enol. Vitic. 56, 104-109.

Minnaar, P.P. \& Booyse, M., 2011. Differentiation among young and market-ready Cabernet Sauvignon, Pinotage and Shiraz wines: Application of canonical discriminant analysis using flavonoid and non-flavonoid compositional data. S. Afr. J. Enol. Vitic. 32, 251-261.

Morato, A., Gómez-Cordovés, M.C., Colomo, B. \& Suárez, J.A., 2005. Cell wall anthocyanin adsorption by different Saccharomyces strains during the fermentation of Vitis vinifera L. cv. Graciano grapes. Eur. Food Res. Tech. $220,341-346$.
Morato, A., González, C. \& Suárez-Lepe, J.A., 2007. Formation of vinylphenolic pyranoanthocyanins by selected yeasts fermenting red grape musts supplemented with hydroxycinnamic acids. Int. J. Food Microbiol. $116,144-152$

Nadal, M. \& Hunter, J.J., 2007. Different wine styles as related to ripening levels of Syrah/R99 grapes. In: Proc. Intervitis Interfructa Conf., April 2007, Stuttgart, Germany.

Noble, A.C. \& Bursick, G.F., 1984. The contribution of glycerol to perceived viscosity and sweetness in white wine. Am. J. Enol. Vitic. 39, 110-112.

Prior, B.A., Toh, T.H., Jolly, N.P., Baccari, C.L. \& Mortimer, R.K., 2000. Impact of yeast breeding for elevated glycerol production on fermentation activity and metabolite formation in Chardonnay. S. Afr. J. Enol. Vitic. 21, 92-99.

Scanes, K.T., Hohmann, S. \& Prior, B.A., 1998. Glycerol production by the yeast Saccharomyces cerevisiae and its relevance to wine: A review. S. Afr. J. Enol. Vitic. 19, 15-21.

Soil Classification Working Group, 1991. A taxonomic system for South Africa. Memoirs on natural agricultural resources of South Africa No. 15, Department of Agricultural Development, Pretoria, South Africa.

Vasserot, Y., Caillet, S. \& Maujean, A., 1997. Study of anthocyanin adsorption by yeast lees. Effect of some physicochemical parameters. Am. J. Enol. Vitic. 48, 433-437.

Vidal, S., Francis, L., Williams, P., Kwiatkowski, M., Gawel, R., Cheynier, W. \& Waters, E., 2004. The mouth-feel properties of polysaccharides and anthocyanins in a wine like medium. Food Chem. 85, 519-525.

Waterhouse, A.L., Price, S.F. \& McCord, J.D., 1999. Reversed-phase high-performance liquid chromatography methods for analysis of wine polyphenols. Meth. Enzym. 299, 113-122. 